\title{
CALIDAD PROTEICA EN SEGREGANTES DE CRUZAS DE DOS FUENTES DEL GEN OPACO-2 CON VARIEDADES ANDINAS DE MAÍZ
}

\section{PROTEIN QUALITY IN SEGREGATING FAMILIES FROM CROSSES AMONG PERUVIAN RACIAL COMPOSITES OF MAIZE WITH TWO SOURCES OF OPAQUE-2 GENE}

\author{
María del Rosario Castro Muñoz y Ricardo Sevilla Panizo ${ }^{1}$
}

\section{Resumen}

Catorce líneas segregantes $\mathrm{F}_{2}$ provenientes de las cruzas realizadas entre los compuestos raciales (C.R.) peruanos con dos pooles andinos, homocigotos para el gen opaco-2 (formados en el CIMMYT con una alta proporción de germoplasma andino), fueron autopolinizadas en Chiquián Perú. El gen opaco 2 aumenta en el grano la cantidad de dos aminoácidos esenciales: lisina y triptófano. Las mazorcas fueron cosechadas y seleccionadas por su parecido al C.R. peruano. Se seleccionaron diez mazorcas de cada línea segregante y se evaluó en cada una: la longitud y el diámetro de la mazorca, el diámetro de la tusa, el diámetro del raquis, la profundidad de grano, y el número de hileras. De cada mazorca se seleccionaron 10 semillas, y se registraron los colores del pericarpio, de la aleurona y del endospermo. Se realizó la comparación de los parámetros morfológicos de las líneas segregantes con los parámetros de los compuestos raciales peruanos. Para comprobar la presencia del gen opaco, que mejora la calidad proteica del grano mediante la reducción de la zeína, se evaluaron químicamente cinco granos de cada mazorca. Se realizó el análisis turbidimétrico de zeína basado en el método de Paulis et al. (1974) modificado por el CIMMYT. La variedad de maíz opaco PMS 267 fue usada como testigo.

Los pooles andinos 1 y 2 mostraron ser buenos progenitores, sin modificar los caracteres andinos de las mazorcas en las poblaciones segregantes. A todos los compuestos raciales se les incorporó este gen. La incorporación del opaco-2 y selección posterior en las progenies autofecundadas no modifica el tipo de grano, ni el color. Se comprobó también que el método de selección de mazorcas parecidas al progenitor peruano en las primeras generaciones de endocría es un buen método, siendo más rápido que el método de retrocruzas para incorporar este gen. En esa forma es posible mantener el gen opaco en una alta frecuencia en la diversidad del maíz en el Perú. Palabras clave: variedades, maíz, gene opaco 2, calidad proteica, Zea mays

Fourteen $\mathrm{F}_{2}$ segregating families, from crosses among Peruvian racial composites of maize with two Andean pools formed with a considerable proportion of Andean germplasm, homocigous for the gene opaque -2 , were selfcrossed. The ears were harvested and selected for their similarities with the racial composites. Ten ears of each family were evaluated by their morphological characteristics: ear length, ear width, cob diameter, rachis diameter, grain depth, and ear row number. Ten seeds representative of each ear were evaluated for their pericarp, aleurone and endosperm colors. Comparisons of the morphological parameters were done between the segregating families and the Peruvian racial composites. In order to check the presence of the opaque 2 gene that improve the quality protein maize by reducing the levels of zein in the kernel, five grains of each ear were analyzed chemically. A rapid turbidimetric analysis for zein based on Paulis et al. (1974) method was carried out. The opaque variety PMS 267 was used as check.

The Andean pools 1 and 2 showed to be good progenitors to incorporate the opaque- 2 gene, without modifying the Andean characters of the ears in the offspring population evaluated. In all the racial composites, the opaque- 2 gene that increases the quantity of two essential amino acids in the grain was introduced. Neither the grain type nor the color was modified. The method of selection of similar ears to the Peruvian progenitor in the first generations of self crosses is a good method, being faster than the backcross method in order to incorporate this gene and to maintain it in the offspring populations. In that way it is possible to maintain the opaque- 2 gene in high frequency in the Peruvian maize diversity.

Key words: varieties, maize, opaque 2 gene, protein quality, prebreeding, Zea mays 


\section{Introducción}

El banco de Germoplasma del Programa Cooperativo de Investigación en Maíz de la UNALM (PCIM) formó 24 compuestos raciales de la sierra del Perú (tierras altas). Cada compuesto fue producto de la recombinación de la mezcla de semillas que pertenecían a una misma raza (Sevilla \& Holle, 2004). Estos compuestos rinden más que la mayoría de sus componentes y la heterosis que se expresa en el compuesto no se pierde en generaciones avanzadas. (Borbor, 1992). El compuesto minimiza la endocría y restablece el nivel de heterocigocidad necesario para adaptar las variedades a las condiciones extremas que caracterizan las altas montañas (Sevilla et al., 2004). Una de las tareas de los fitomejoradores de maíz en regiones de mucha diversidad genética es la de crear metodologías de mejoramiento sostenible $\mathrm{y}$ conservativo, de tal manera que los caracteres obtenidos durante el proceso evolutivo no se pierdan por erosión genética (Sevilla, 1993).

Las diversas razas de maíz amiláceo representan un porcentaje muy significativo en la dieta de los pobladores de la sierra del Perú, que consumen maíz directamente en diversas formas como cancha (tostado) o mote (hervido) (Aguilar et al., 1974). Sin embargo, las zeínas (prolaminas), que son las proteínas que representan el 52\% del nitrógeno del grano tienen baja calidad proteica (Tsai, 1983).

En 1963, se descubrió en el maíz un mutante opaco 2, que tiene mayor contenido de lisina en la proteína $(4 \%)$ que los encontrados en los maíces normales (2\%) (Mertz et al., 1964), así como el doble del nivel de triptófano (Misra et al., 1972). El maíz opaco - 2 puede reducir en un $70 \%$ el contenido de zeína en estado homocigota (Wall \& Bietz, 1987). Además, cuando es ofrecido en la dieta como única fuente de proteína, presenta un valor biológico de 87 \% comparado con la caseína de la leche (Bressani et al., 1969). Sin embargo, los cultivares de maíz opaco 2 no fueron aceptados por los agricultores debido a que presentan reducción en el potencial de rendimiento en comparación con la versión normal (Singh \& Asnini, 1975) y otras características agronómicas no deseadas (Ortega et al., 1975; NRC, 1988; Catacora, 1987; Villegas et al., 1992).

En el Perú, algunas variedades de granos duros se lograron convertir a opacos, tales como el PMS-266 y el PMS-267, utilizando la técnica de la retrocruza (Manrique, 1997). Las variedades de granos amiláceos (andinos) portan el gen harinoso-1 ( $\left.\mathrm{fl}_{1}\right)$, y el fenotipo de grano de muchas variedades es idéntico al del mutante opaco-2 $\left(\mathrm{o}_{2}\right)$. La mayoría de las características organolépticas del grano de las variedades nativas no cambian cuando se introduce el gene opaco-2. (Comunicación personal F. Scheuch), además los maíces opacos no pierden su calidad proteica cuando se tuestan o hierven (Aguilar et al., 1974). Sin embargo, el rendimiento se redujo notablemente (Catacora, 1987).

La retrocruza es el método convencional para incorporar genes en variedades adaptadas a la sierra. Este método tiene las siguientes desventajas: (a) son necesarias muchas generaciones de retrocruza para obtener resultados deseados y (b) en cada generación de retrocruza se presenta la dificultad de distinguir a simple vista un grano opaco de un maíz amiláceo andino normal. Por tales motivos, se requieren métodos más eficientes para disminuir el tiempo de incorporación de genes para mantener en los compuestos raciales un buen nivel de diversidad, así como para identificar al gen opaco en las poblaciones segregantes. Los objetivos de la presente investigación son: 1) Verificar la incorporación del gen opaco-2 en familias $\mathrm{F}_{3}$ provenientes de cruzas de dos fuentes del gen opaco -2 con variedades andinas de maíz y 2) Comprobar si el fenotipo de las mazorcas y granos de los segregantes difiere del fenotipo de las variedades peruanas.

\section{Materiales y métodos}

\section{Descripción del material experimental}

El PCIM de la UNALM recibió del Centro Internacional de Mejoramiento de Maíz y Trigo (CIMMYT) tres poblaciones de pooles andinos, homocigotas para el gen opaco-2; que tienen el fenotipo de grano similar al de algunas razas de la sierra del Perú y mayor posibilidad de adaptación a las tierras altas. Estos pooles se cruzaron con veinticuatro compuestos raciales (C.R.) de razas de sierra. La progenie $\mathrm{F}_{1}$ se sembró y autofecundó. Se cosecharon 8.832 autopolinizaciones (mazorcas $\mathrm{F}_{1}$ con semillas $\mathrm{F}_{2}$ ), se analizaron todos los resultados de la autopolinización y se realizó dentro de cada familia una selección fenotípica por aspecto, similitud $\mathrm{y}$ resistencia a heladas.

Procedimiento experimental

La progenie $F_{2}$ fue sembrada y autopolinizada en Chiquián (2900 msnm), Ancash - Perú. Se cosecharon 1294 mazorcas, utilizándose en la presente investigación aquellas que pertenecían a las cruzas presentadas en la Tabla 1.

Evaluación morfológica de las mazorcas y granos

Se contó el número de mazorcas totales, el número de mazorcas similares al compuesto racial peruano y el número de mazorcas dañadas por hongos que causan la pudrición de la mazorca. Se seleccionaron dentro de cada línea segregante 10 mazorcas parecidas al Compuesto Racial (C.R.) y se evaluó: a) longitud de la mazorca, medida en centímetros desde la base a la punta de la mazorca; b) el diámetro de mazorca medido en centímetros en la parte media de la mazorca; c) el diámetro de la tusa, la distancia medida 
en centímetros entre los extremos opuestos de las glumas; d) el diámetro del raquis, expresado en centímetros y corresponde a la medida del diámetro tomando los extremos opuestos de la base de las glumas; e) la profundidad de grano, expresada en centímetros, es la medida de la diferencia entre el diámetro de la mazorca y el diámetro del raquis dividido entre dos; y f) el número de hileras.

Para el análisis estadístico de los resultados de estas determinaciones morfológicas, se utilizó la prueba de $\mathrm{t}$ de student de comparación de medias, entre la media poblacional del compuesto racial (datos tomados del libro de Razas de Maíz de Grobman et al., 1961) con la media de las líneas segregantes. La prueba t se realizó con $9 \mathrm{gl}$.

Se seleccionaron 10 granos representativos de la mazorca y se evaluó: a) el color del pericarpio, que corresponde al color del tejido más externo del grano; b) el color de la aleurona, que corresponde al color de la hilera de células que está debajo del pericarpio, y c) el color del endospermo, que corresponde al color del tejido que está debajo de la capa de aleurona. Los resultados de los análisis del color se compararon con los colores que presentan las diferentes razas peruanas.

Determinación de la calidad proteica del maíz

Se tomaron cinco granos de cada mazorca para comprobar químicamente la presencia del gen opaco, de tal modo, que si cinco granos de una misma mazorca son opacos, hay una altísima probabilidad de que todos los granos sean homocigotos o2/o2 en la mazorca. Se utilizó a la variedad de maíz opaco, PMS 267 del PCIM, como testigo.

Se usó el análisis turbidimétrico de zeína basado en el método de Paulis et al., (1974) modificado por el CIMMYT; que es una metodología rápida, simple, económica e indirecta para determinar el contenido de lisina. La concentración de Zeína es inversa al contenido de Lisina (NRC, 1988). La alta turbidez de las muestras indica alto contenido de zeína y por lo tanto una baja calidad proteínica. Una baja turbidez o bajo contenido de zeína indica buena calidad proteínica en la muestra.

Antes de proceder al análisis químico, se preparó la muestra de la siguiente manera: los granos de maíz se remojaron en agua por 20 minutos y luego se retiró el pericarpio y el germen para obtener solamente endospermo. La muestra se dejó secar a temperatura ambiente durante la noche. Las muestras se molieron en un molino con malla $0.5 \mathrm{~mm}$. Se pesó $100 \mathrm{mg}$ de muestra finamente molida y sin desengrasar, y se colocó en un tubo de vidrio de 14 x $150 \mathrm{~mm}$ con tapa rosca (la muestra no debe tener más de 48 horas de almacenamiento después de molida, comunicación personal de E. Villegas del CIMMYT). Se agregó 10 $\mathrm{ml}$ de solución extractora (alcohol etílico al 70\%, conteniendo acetato de sodio al $0.5 \%$ ) y se taparon los tubos. Las muestras fueron agitadas en un vortex por 2 minutos, dos veces con un lapso de 10 minutos entre una agitación y la siguiente. Luego se filtraron los extractos con papel filtro y fueron recibidos en un tubo de ensayo de 13 x $100 \mathrm{~mm}$. Se transfirió una alícuota de $1 \mathrm{ml}$ a tubos calibrados para el colorímetro. Seguidamente se añadió una solución 3 $\mathrm{ml}$ de $\mathrm{NaCl}$ al $1 \%$ con una pipeta volumétrica o automática, para asegurar que la mezcla sea perfectamente homogénea. Se dejó reposar los tubos a temperatura ambiente durante 15 minutos. Se eliminaron las burbujas de aire en los tubos y se leyó la absorbancia (D.O. = densidad óptica) en el espectrofotómetro a una longitud de onda $\lambda=590 \mathrm{~nm}$.

Se seleccionaron aquellas muestras con los valores de densidad óptica (turbidez) más bajos. Dichos materiales tendrían el contenido de zeína más bajo y el de lisina más alto. Para el análisis de los resultados por turbidimetría se utilizó el paquete estadístico SAS versión 9 año 2005. Se planteó la hipótesis nula de igualdad de medias de absorbancia para los segregantes de los pooles 1 y 2 , versus la alternativa de que los segregantes de ambos pooles son diferentes. Se realizó el Análisis de Variancia para los valores de absorbancia (D.O.), considerando el promedio de absorbancia de los segregantes como tratamientos. Luego se realizó una prueba de comparación de medias usando la prueba de F para contrastes.

Para determinar que muestras tienen alto contenido y diferenciarlas de las de bajo contenido, se analizaron muestras de maíces de los pooles andinos, los compuestos raciales y del maíz opaco PMS 267 utilizado como testigo.

Para determinar la frecuencia genotípica del gen opaco en las familias segregantes, se consideró que si los cinco granos analizados por mazorca eran opacos, la mazorca era homocigoto recesiva, si al menos un grano no era opaco la mazorca era heterocigota y si ningún grano era opaco la mazorca era homocigota dominante. Para hallar la frecuencia génica del gen opaco en toda la población analizada, se contó el número total de individuos (granos opacos) $\mathrm{y}$ se dividió entre el total de individuos de la población $\mathrm{F}_{3}$, y a este valor se le sacó la raíz cuadrada.

\section{Resultados y discusión}

\section{Similitud morfológica}

De 1294 mazorcas cosechadas, se seleccionaron 493 mazorcas completamente sanas y similares a las razas peruanas El método sólo tiene valor si los segregantes opaco-2 se parecen morfológicamente a las razas peruanas, cualquier desviación a la morfología de las mazorcas peruanas es rechazada por los consumidores. Además varios caracteres morfológicos de la mazorca de maíz son mecanismos de evasión al frío (Evaristo, 1995). La Foto 1 muestra las mazorcas de los segregantes de la cruza C.R. San Gerónimo Huancavelicano x Pool 2. La Tabla 2 
muestra los resultados de la prueba de $t$ de student de comparación de medias de los parámetros morfológicos de las mazorcas de los compuestos raciales con los segregantes de las cruzas. En esta tabla se observa que en los parámetros de longitud y ancho de mazorca, diámetro de tusa y diámetro de raquis de los C.R.: Huancavelicano, Huayleño, Morocho y San Gerónimo Huancavelicano, y de sus segregantes no existen diferencias significativas. Mientras que si se observan diferencias entre los compuestos raciales con los segregantes de las cruzas: C.R. Paro $x$ Pool 1 (diámetro de la raquis más delgado); C.R. Paro x Pool 1 y C.R. Paro x Pool 2 (tienen una profundidad del grano mayor); C.R. Marañón x Pool 1(mazorca menos alargada); C.R. Marañón x Pool 2 (mazorca menos ancha y granos más pequeños) y Morocho Cajabambino x Pooll y Morocho Cajabambino x Pool 2 (las mazorcas son más anchas).

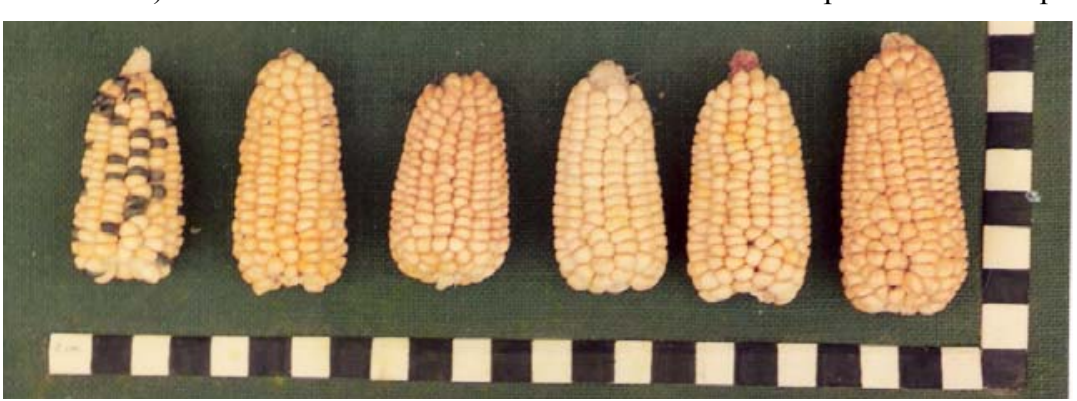

Foto 1. Mazorcas de los segregantes de la cruza san gerónimo huancavelicano x pool 2.

Referente al número de hileras, la Tabla 2 muestra que la mayoría de los segregantes no tienen diferencias con las razas, excepto los segregantes de las cruzas Huancavelicano x Pool 1 y Huayleño x Pool 1 que muestran un número mayor de hileras, mientras que los segregantes de la cruza Marañón x Pool 2 muestran un número menor de hileras. Ninguna de estas diferencias son tan marcadas como para descartar las cruzas. Así mismo, se observó que en la mayoría de los segregantes por autofecundación, excepto en aquellos derivados del compuesto racial Marañón, no hay evidencia de depresión por endocría en caracteres como largo y ancho de mazorca. Ese efecto existió pero se eliminó al seleccionar las mazorcas más parecidas al progenitor peruano. En relación al aspecto, muchas

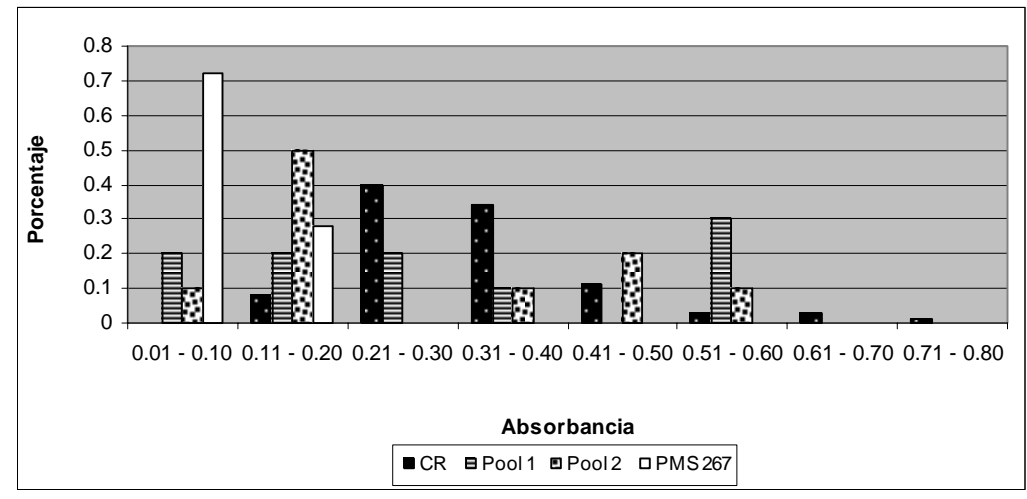

Figura 1. Distribución de los granos en cada rango de absorbancia. mazorcas polinizadas no presentaron una buena conformación, fueron diferentes al tipo de maíz andino, y por ello son fáciles de detectar y eliminar.

El color del grano es un carácter morfológico cualitativo importante para la identificación de razas. En la Tabla 3 se muestran los colores más frecuentes en los segregantes comparados con las razas originales. No hay ninguna variación en el color del endospermo; todos los segregantes presentan coloración blanca como las razas. El color de la aleurona y del pericarpio de casi todos los segregantes es típico de las razas. Entre las excepciones mostradas en esta tabla, en la columna "no encontradas en las razas", aparece el color crema que podría ser un efecto ambiental.

Análisis turbidimétrico de zeína

En la Figura 1 se muestra la distribución de los granos en cada rango de absorbancia $(\lambda=590 \mathrm{~nm})$ de los compuestos raciales peruanos, de los pooles andinos y del testigo (PMS 267). En esta figura se observa que para el caso del testigo, los valores de absorbancia son menores de 0.20 , la frecuencia más alta de estos granos opacos está en el rango de absorbancia de 0.01 a 0.10. Los compuestos raciales tienen valores $\mathrm{de}$ absorbancia que van desde 0.11 a 0.80 . Encontrándose las frecuencias más altas en el rango entre 0.20 y 0.40 . Los pooles andinos mostraron un amplio rango de absorbancia que va desde el valor de 0.01 a 0.60 . Estos resultados nos inducen a pensar que podría haber habido contaminación del pool andino 1 y 2 durante el proceso de regeneración. En esta investigación se decidió empíricamente que una absorbancia (D.O.) de 0.20 correspondía a un grano opaco, porque los valores de absorbancia del testigo no fueron superiores a este valor. En el rango de 0.20 a 0.30 hay serias dudas que nos impiden generalizar. 


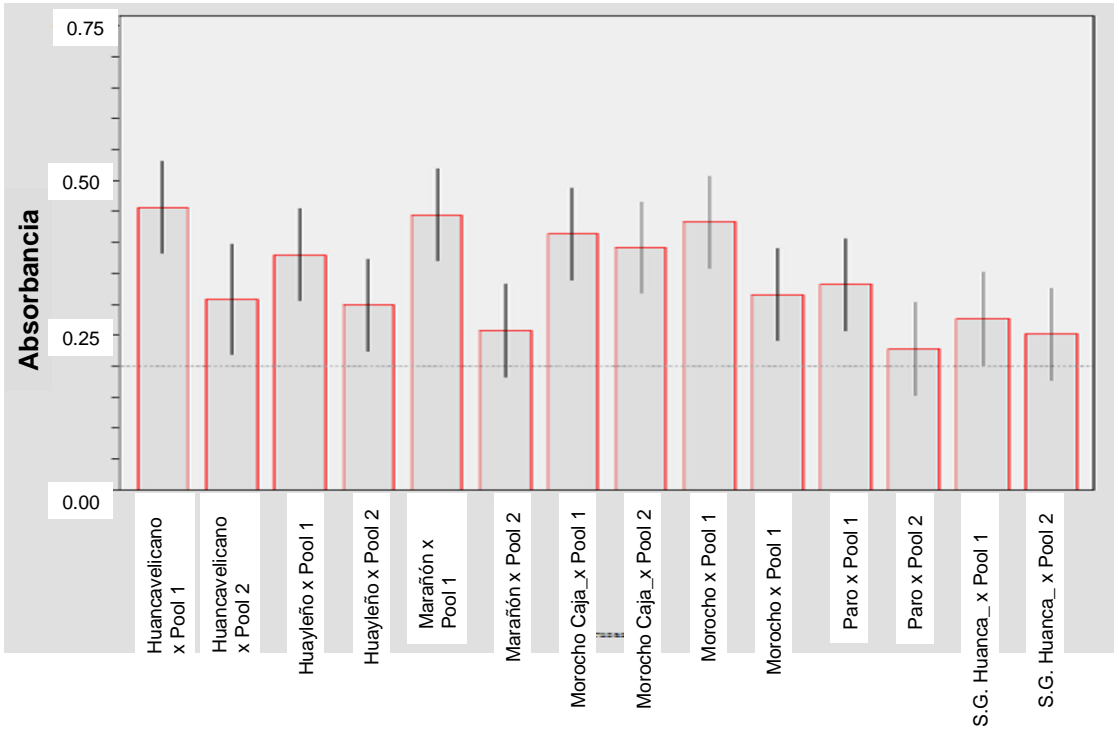

Figura 2. Histograma de los valores promedio de absorbancia de los segregantes.

En la Tabla 4 se presentan los resultados de la prueba turbidimétrica realizada a las líneas segregantes. En todos los casos, excepto en los segregantes de la cruza C.R. Huancavelicano x Pool 2, se analizaron un total de 50 granos ( 5 granos por mazorca producidos por la planta $\mathrm{F}_{2}$ ). La Hipótesis de igualdad de medias de absorbancia para los segregantes de las cruzas, resultó significativa en el análisis de variancia, con un valor de $\mathrm{F}=4.15$ con 13 y 123 gl (Tabla 5). De allí que nos interesó conocer a qué se deben estas diferencias. Para esto, se estimó la diferencia de absorbancia promedio de ambos grupos mediante el cálculo de la diferencia observada promedio. Se usó la prueba $\mathrm{F}$ para contrastes, con 1 y 123 grados de libertad, para comparar si las progenies de las cruzas con Pool 1 son iguales o no a las progenies de las cruzas con Pool 2 y probar que la diferencia promedio de absorbancia de ambos grupos es igual a 0 (Tabla 6). Así, se observa que la diferencia estimada es igual a 0.6843 (Suma de los promedios de cruzas de los C.R. por Pool 1 menos la suma de los promedios de cruzas C.R. por Pool 2). Podemos concluir, que las progenies derivadas de Pool 1 presentan una absorbancia promedio mayor que las progenies derivadas de Pool 2 (diferencia es igual a 0.6843: $7=$ 0.097). El histograma de los valores promedio de absorbancia de todos los

segregantes es presentado en la Figura 2. Se concluye por los tanto que las progenies derivadas de las cruzas de los C.R. por Pool Andino 2 muestran valores menores de absorbancia que las derivadas de las cruzas de los C.R. por Pool Andino $\quad 1 . \quad$ Los segregantes derivados de las cruzas de los C.R. por Pool Andino 1 tienen una frecuencia de granos considerados opacos de $15 \%$, mientras que los segregantes derivados de las cruzas de los C.R. por Pool andino 2 tienen una frecuencia de granos considerados opacos de 30\% (Tabla 4). Sin embargo, no se puede concluir que el Pool Andino 2 es un mejor donador del gen opaco-2 que el Pool Andino 1, porque parece ser que el pool andino 1 podría estar contaminado (Figura 1) y además la clasificación de normal y opaco podría estar viciada, al ser la prueba turbidimétrica una medida indirecta del contenido de lisina, basada en el contenido de zeína.

La progenie de la mazorca de una planta $F_{2}$ es la semilla $\mathrm{F}_{3}$; se espera en esta última generación de autofecundación, el $37.5 \% \quad(3 / 8)$ de individuos homocigotas opaco-2 y el $62.5 \%(5 / 8)$ de granos

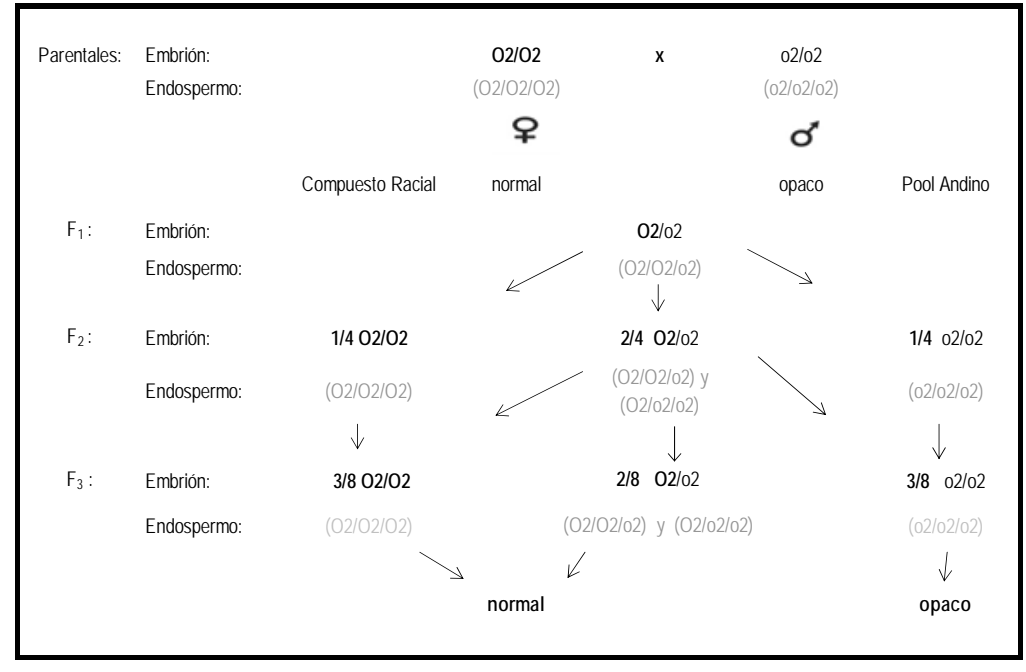

Figura 3. Frecuencia esperada de granos opacos y normales en la $f_{3}$ de una cruza normal por opaco. 
normales (Figura 3). La frecuencia de los granos opacos en toda la población $\mathrm{F}_{3}$ observada fue $22.6 \%$ (Tabla 4), y la frecuencia del gen opaco 2 (o2) observada es igual a 0.476 . Se reconoce que por azar, no es posible esperar un $37,5 \%$ de opacos en todas las razas, porque una muestra de 10 mazorcas por línea segregante es muy pequeña. Los resultados presentados en la figura 4, muestran por ejemplo dos casos extremos; el CR Huancavelicano x Pool 1 con una dispersión cercana a $62.5 \%$ normales y $37.5 \%$ opacos (Figura 4 a).

En la Figura 4 b se muestra la dispersión del CR Paro $\mathrm{x}$ Pool 2, donde parecen que todos los granos son homocigotas opaco-2. Estos valores nos indican que el valor de absorbancia de zeína es útil para detectar granos opacos en una población segregante, pero hasta que no se ajuste el valor que separe opacos de normales, la metodología no puede ser usada para
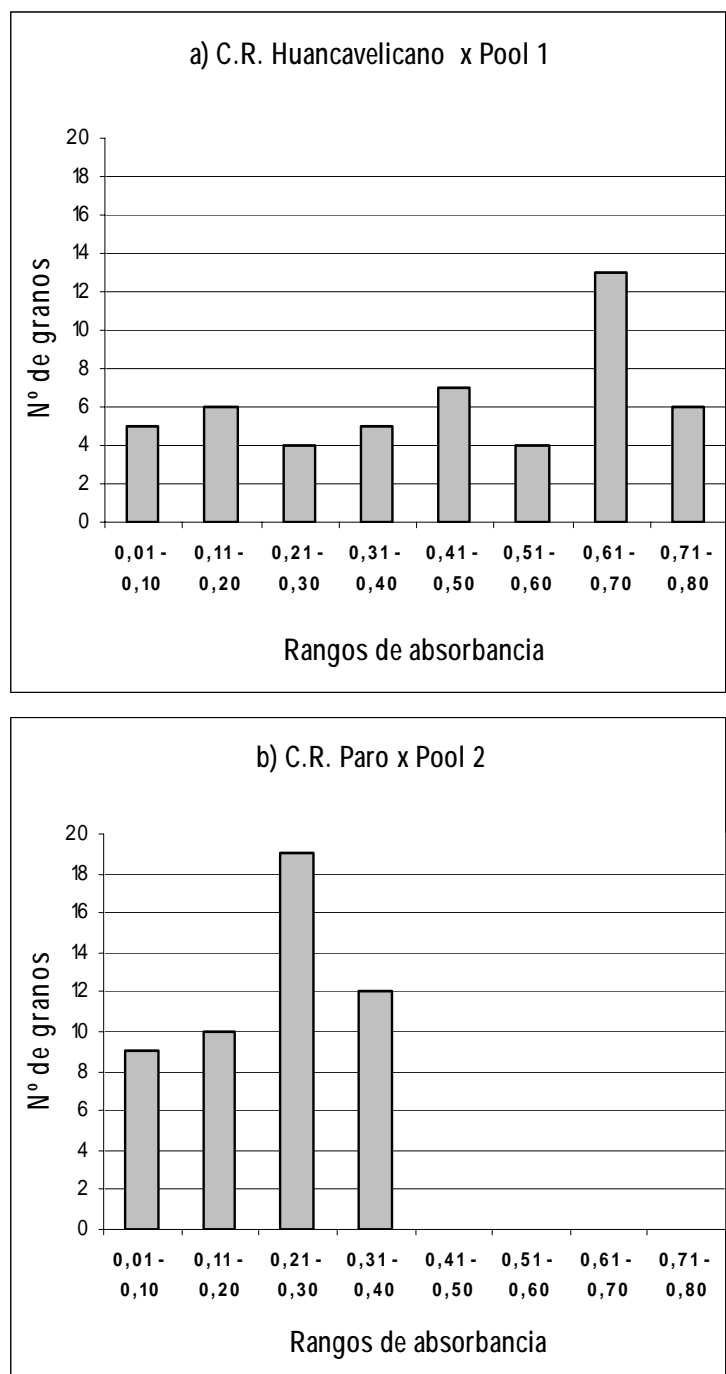

Figura 4. Distribución de la absorbancia delos segregantes de las cruzas c.r.huancavelicano x pool 1 y c.r.paro x pool 2 análisis genéticos. Por ejemplo, la frecuencia del alelo opaco 2 en la descendencia de las cruzas; se supone que sigue siendo 0.5 , como en la $\mathrm{F} 1$, porque en el proceso no ha habido selección en contra o favor de opaco y se supone que no ha habido contaminación (migración). Sin embargo, como ya se ha discutido, puede haber deriva génica por el uso de poblaciones pequeñas. Esto puede haber cambiado la frecuencia del opaco-2 hacia cualquier dirección, sea mayor o menor de 0.5. La frecuencia observada del gen en este análisis fue de 0.476. Otro factor que hay que considerar es que los pooles andinos podrían estar contaminados (Figura 3), esta sería otra de las razones que explicaría el porque hay una mayor frecuencia de maíces normales en la población.

\section{Conclusiones}

Los pooles andinos I y II mostraron ser buenos progenitores para incorporar el gen opaco-2, sin modificar los caracteres andinos de las mazorcas en las poblaciones segregantes.

A todos los compuestos raciales se les introdujo el gen opaco-2, que aumenta la cantidad de dos aminoácidos esenciales en el grano. La incorporación del opaco-2 y selección posterior en las progenies autofecundadas de las retrocruzas no modifica la textura, ni el color del grano.

Se comprobó que el método de selección de mazorcas parecidas al progenitor peruano en las primeras generaciones de endocría es un buen método, siendo más rápido que el método de retrocruzas para incorporar el gen opaco-2 y mantenerlo en las poblaciones segregantes.

\section{Recomendaciones}

Ajustar el método turbidimétrico para definir con mayor precisión el valor que separa los maíces normales de los de alta calidad proteica.

Mantener los pooles andinos 1 y 2 y verificar si son homocigotas al gen opaco-2, en el caso de que haya habido contaminación.

Poner los pooles andinos 1 y 2 a disposición de los programas de mejoramiento de la sierra del Perú, para que puedan contar con un método rápido de mejoramiento de la calidad proteica del grano.

\section{Agradecimientos}

A la M Sc. Miriam Borbor por darnos su apoyo para realizar este trabajo.

A la Dra. Consuelo Arellano por brindarnos su apoyo con los Análisis Estadísticos.

Al CONCYTEC por su apoyo en la financiación parcial del presente trabajo.

Al Programa Cooperativo de Investigaciones en Maíz (PCIM) de la UNALM, por brindarnos sus instalaciones, su apoyo financiero y por ser una constante escuela al servicio de la investigación. 


\section{Literatura Citada}

Aguilar T., Manrique A. \& Rojas V. 1974. Valor biológico del maíz opaco-2 en cancha y mote. Archivos Latinoamericanos de Nutrición. 24: 379-394.

Borbor M. 1992. Evaluación de componentes de rendimiento y características morfológicas de compuestos raciales de maíz en la sierra del Perú. Tesis de Magister Scientiae. UNALM. La Molina, Lima, Perú.

Bressani R., Alvarado J. \& Viteri F. 1969. Evaluación en niños de la calidad de la proteína del maíz opaco-2. Archivos Latinoamericanos de Nutrición. 19:129-140.

Catacora L. 1987. Selección para resistencia al Puka.Punchu en la sierra del Perú. Tesis de Magister Scientiae. UNALM. Lima - Perú.

Evaristo Chipana J. 1995. Características morfológicas de la mazorca de maíz (Zea mays L.), asociadas a la tolerancia al frío en germoplasma peruano y foráneo. Tesis Magister Scientiae .UNALM. Lima, Perú.

Grobman A., Salhuana W. \& Sevilla R. 1961. Races of maize in Peru, their origins, evolution and classification. National Academy of Sciences - National Research Council. Publication 915. Washington, D.C. USA

Manrique A. 1997. El maíz en el Perú. Ed. CONCYTEC. Serie tecnológica $\mathrm{N}^{\circ} 10$. Lima, Perú.

Mertz E.T., Bates L.S. \& Nelson O.E. 1964. Mutant gene that changes the protein composition and increases the lysine content of maize endosperm. Science. 145(3629): 279-280.

Misra P.S., Jambunathan R., Mertz E.T., Glover D.V., Barbosa H.M. \& McWhirter K.S. 1972. Endosperm protein synthesis in maize mutants with increased lysine content. Science. 176(4042): 1425-1427.

National Research Council. (NRC). 1988. Quality protein maize. Washington: National Academy. Washington, DC.

Ortega A., De León C., Granados G. \& Vasal S.K. 1975. Disease insect interactions in quality protein maize.
Págs: 178-192. In: Mertz E.T. (Ed). High Quality Protein Maize. Dowden, Hutchinson and Ross. Inc. Stroudsbug, . Pennsylvania, USA.

Paulis J.W., Wall J.S. \& Kwolek W.F. 1974. A rapid turbidimetric analysis for zein in corn and its correlation with lysine content. Journal of Agriculture and Food Chemistry. 22(2): 313-317.

Sevilla R. 1993. Variation in modern Andean maize and its implications for prehistoric patterns. In: Johannessen S. $\&$ Hastorf C.A. (eds) Corn and Culture in the Prehistoric New World. Westview Press. San Francisco. \& Holle M. 2004. Recursos Genéticos Vegetales. Luis León Asociados S.R.L. (Eds). Lima.

Singh J. \& Asnini V.L. 1975. Quality in maize through opaque-2. In: Mertz E.T.(Ed.). High Quality Protein Maize. Dowden, Hutchinson and Ross. Inc. Stroudsbug. Pennsylvania, USA.

Tsai C.Y. 1983. Genetics of storage protein in Maize. Págs: 103-138. In: Plant Breeding Reviews. Volume 1. Avi. Pub. Co. Westport, USA.

Villegas E., Vasal S.K. \& Bjarnason M. 1992. Quality protein maize - what is it and how was it developed. Págs: 27-48. In: E.T. Mertz (Ed). Quality protein maize. St Paul, MN, USA, The American Association of Cereal Chemists.

Wall J.S. \& Bietz J.A. 1987. Differences in corn endosperm proteins in developing seeds of normal and opaque-2 corn. Cereal Chemistry. 64:275-280.

\section{Tablas citadas en el texto}

Tabla 1. Relación de las Cruzas entre los Compuestos Raciales y los Pooles Andinos

\begin{tabular}{|c|c|}
\hline 1) C.R.Huancavelicano $\mathrm{x}$ Pool 1 (x)(x) & 8) C.R.Huancavelicano x Pool 2 (x)(x) \\
\hline 2) C.R.Huayleño $x$ Pool 1 (x)(x) & 9) C.R.Huayleño x Pool 2 (x)(x) \\
\hline 3) C.R.Morocho $x$ Pool 1 (x)(x) & 10) C.R.Morocho $x$ Pool $2(x)(x)$ \\
\hline 4) C.R.Paro $x$ Pool $1(x)(x)$ & 11) C.R.Paro $x$ Pool $2(x)(x)$ \\
\hline 5) C.R.San Gerónimo Huancavelicano $x$ Pool 1 (x)(x) & 12) C.R.San Gerónimo Huancavelicano x Pool $2(\mathrm{x})(\mathrm{x})$ \\
\hline 6) C.R.Marañón x Pool 1 (x)(x) & 13) C.R.Marañón $x$ Pool $2(x)(x)$ \\
\hline 7) C.R.Morocho Cajabambino $x$ Pool 1 (x)(x) & 14) C.R.Morocho Cajabambino $x$ Pool 2 (x)(x) \\
\hline
\end{tabular}


PREMEJORAMIENTO DE LA CALIDAD PROTEICA EN LAS VARIEDADES ANDINAS DE MAÍZ Enero - Diciembre 2008

Tabla 2. Comparación de los caracteres morfológicos de las mazorcas

\begin{tabular}{|c|c|c|c|c|c|c|c|c|c|c|c|c|}
\hline \multirow[b]{2}{*}{ Compuestos raciales y Segregantes } & \multicolumn{2}{|c|}{$\begin{array}{l}\text { Largo de } \\
\text { Mazorca }\end{array}$} & \multicolumn{2}{|c|}{$\begin{array}{l}\text { Ancho de } \\
\text { Mazorca }\end{array}$} & \multicolumn{2}{|c|}{$\begin{array}{c}\text { Diámetro de } \\
\text { la tusa }\end{array}$} & \multicolumn{2}{|c|}{$\begin{array}{c}\text { Diámetro del } \\
\text { caquis }\end{array}$} & \multicolumn{2}{|c|}{$\begin{array}{c}\text { Profundidad } \\
\text { del Grano }\end{array}$} & \multicolumn{2}{|c|}{$\mathbf{N}^{0}$ de hileras } \\
\hline & $\begin{array}{l}\text { Prom } \\
(\mathrm{cm})\end{array}$ & $\mathrm{t}$ cal & $\begin{array}{l}\text { Prom } \\
(\mathrm{cm})\end{array}$ & $\mathrm{t}$ cal & $\begin{array}{l}\text { Prom } \\
(\mathrm{cm})\end{array}$ & $\mathrm{t}$ cal & $\begin{array}{l}\text { Prom } \\
(\mathrm{cm})\end{array}$ & $\mathrm{t}$ cal & $\begin{array}{l}\text { Prom } \\
(\mathrm{cm})\end{array}$ & $\mathrm{t}$ cal & Prom & $\mathrm{t}$ cal \\
\hline C.R. Huancavelicano & 11.45 & & 4.65 & & 2.05 & & 1.30 & & 1.68 & & 8.75 & \\
\hline C.R. Huancavelicano x Pool 1 (x)(x) & 12.08 & 0.60 & 4.71 & 0.12 & 2.45 & 1.08 & 1.54 & 0.93 & 1.58 & -0.47 & 13.00 & $2.501^{*}$ \\
\hline C.R. Huancavelicanox Pool 2 (x)(x) & 11.77 & 0.32 & 4.56 & -0.23 & 2.31 & 0.78 & 1.34 & 0.20 & 1.62 & 0.41 & 12.57 & 1.79 \\
\hline C.R. Huayleño & 11.63 & & 4.20 & & 2.10 & & 1.14 & & 1.53 & & 8.60 & \\
\hline C.R. Huayleño x Pool 1 (x)(x) & 12.59 & 0.46 & 4.95 & 1.86 & 2.33 & 0.98 & 1.36 & 0.81 & 1.80 & 1.93 & 13.00 & $4.17 * *$ \\
\hline C.R. Huayleño x Pool $2(\mathrm{x})(\mathrm{x})$ & 12.50 & 0.70 & 4.60 & 0.93 & 2.17 & 0.32 & 1.20 & 0.36 & 1.55 & 0.20 & 11.20 & 1.54 \\
\hline C.R. Morocho & 12.15 & & 4.25 & & 2.24 & & 1.32 & & 1.47 & & 10.75 & \\
\hline C.R. Morocho x Pool 1(x)(x) & 12.25 & 0.09 & 4.45 & 0.53 & 2.35 & 0.57 & 1.40 & 0.40 & 1.52 & 0.45 & 11.60 & 0.46 \\
\hline C.R. Morocho x Pool 2 (x)(x) & 11.19 & -0.33 & 4.37 & 0.36 & 2.23 & -0.05 & 1.30 & -0.09 & 1.53 & 0.44 & 12.00 & 0.66 \\
\hline C.R. Paro & 11.49 & & 4.33 & & 2.94 & & 2.01 & & 1.16 & & 14.66 & \\
\hline C.R. Paro x Pool 1 (x)(x) & 11.47 & -0.02 & 5.01 & 1.92 & 2.45 & -1.90 & 1.39 & $2.754 *$ & 1.81 & $4.32 * *$ & 13.80 & -0.58 \\
\hline C.R. Paro $x$ Pool $2(x)(x)$ & 12.24 & 0.51 & 4.68 & 1.06 & 2.40 & -2.22 & 1.54 & -1.56 & 1.53 & $2.67 *$ & 12.40 & -1.79 \\
\hline C.R. San Gerónimo Huancavelicano & 8.10 & & 4.70 & & 2.27 & & 1.46 & & 1.62 & & 11.12 & \\
\hline $\begin{array}{l}\text { C.R. S.G. Huancavelicano x Pool } 1 \\
(\mathrm{x})(\mathrm{x})\end{array}$ & 11.20 & 1.75 & 4.82 & 0.15 & 2.34 & 0.24 & 1.43 & -0.07 & 1.69 & 0.28 & 12.30 & 0.49 \\
\hline $\begin{array}{l}\text { C.R. S.G. Huancavelicano x Pool } 2 \\
(\mathrm{x})(\mathrm{x})\end{array}$ & 12.15 & 1.70 & 4.52 & -0.58 & 2.45 & 0.70 & 1.47 & 0.02 & 1.53 & -0.67 & 12.20 & 0.73 \\
\hline C.R. Marañon & 16.68 & & 4.98 & & 2.16 & & 1.21 & & 1.89 & & 14.98 & \\
\hline C.R. Marañon x pool 1(x)(x) & 13.23 & $2.48^{*}$ & 4.48 & -1.43 & 2.14 & -0.10 & 1.24 & 0.15 & 1.62 & -1.47 & 13.80 & -0.59 \\
\hline C.R. Marañon x pool 2(x)(x) & 13.92 & -1.19 & 4.30 & $2.37 *$ & 2.30 & 0.54 & 1.37 & 0.62 & 1.47 & $2.585^{*}$ & 12.20 & $2.45 *$ \\
\hline C.R. Morocho Cajabambino & 14.15 & & 3.60 & & 2.24 & & 1.22 & & 1.47 & & 10.67 & \\
\hline $\begin{array}{l}\text { C.R. Morocho Cajabambino x Pool } 1 \\
\text { (x)(x) }\end{array}$ & 13.20 & -0.74 & 4.40 & $2.619^{*}$ & 2.40 & 0.77 & 1.29 & 0.33 & 1.56 & 0.65 & 13.20 & 1.00 \\
\hline $\begin{array}{l}\text { C.R. Morocho Cajabambino x Pool } 2 \\
\text { (x)(x) }\end{array}$ & 13.33 & -0.49 & 4.53 & $2.511 *$ & 2.42 & 0.75 & 1.40 & 0.74 & 1.56 & 0.72 & 13.20 & 1.31 \\
\hline
\end{tabular}

Tabla 3. Caracteres cualitativos de las mazorcas segregantes, fenotipos más frecuentes comparados con las razas progenitoras

\begin{tabular}{|c|c|c|c|}
\hline \multirow[b]{2}{*}{ Segregantes de las Cruzas } & \multirow[b]{2}{*}{ Características } & \multicolumn{2}{|l|}{ Colores } \\
\hline & & Encontrados en las razas & $\begin{array}{l}\text { No encontrados en } \\
\text { las razas }\end{array}$ \\
\hline \multirow{4}{*}{ C.R. Huancavelicano x Pooles Andinos (x)(x) } & Pericarpio & incoloro, amarillo & crema, anaranjado \\
\hline & Aleurona & amarillo & crema \\
\hline & Endospermo & blanco & \\
\hline & Pericarpio & amarillo, incoloro, rojo anaranjado & \\
\hline \multirow[t]{2}{*}{ C.R. Huayleño x Pooles Andinos (x)(x) } & Aleurona & incoloro & crema \\
\hline & Endospermo & blanco & \\
\hline \multirow{3}{*}{ C.R. Morocho x Pooles Andinos (x)(x) } & Pericarpio & $\begin{array}{l}\text { Amarillo, anaranjado, rojo, pardo, } \\
\text { guinda, incoloro }\end{array}$ & crema perlado, crema \\
\hline & Aleurona & amarillo, incoloro & crema \\
\hline & Endospermo & blanco & \\
\hline \multirow{3}{*}{ C.R. Paro x Pooles Andinos (x)(x) } & Pericarpio & $\begin{array}{l}\text { incoloro, amarillo, rojo capa } \\
\text { blanca, anaranjado }\end{array}$ & crema \\
\hline & Aleurona & amarillo & crema \\
\hline & Endospermo & blanco & \\
\hline \multirow{3}{*}{$\begin{array}{l}\text { C.R. San Gerónimo Huancavelicano x Pooles Andinos } \\
\qquad(\mathrm{x})(\mathrm{x})\end{array}$} & Pericarpio & incoloro, pardo, amarillo & \\
\hline & Aleurona & amarillo & crema \\
\hline & Endospermo & blanco & \\
\hline \multirow{3}{*}{ C.R. Marañon x Pooles Andinos (x)(x) } & Pericarpio & $\begin{array}{l}\text { amarillo, incoloro, rojo, } \\
\text { anaranjado }\end{array}$ & crema \\
\hline & Aleurona & anaranjado & crema \\
\hline & Endospermo & blanco & \\
\hline \multirow{3}{*}{ C.R. Morocho Cajabambino x Pooles Andinos (x)(x) } & Pericarpio & incoloro, amarillo & crema \\
\hline & Aleurona & Amarillo, blanco & crema \\
\hline & Endospermo & blanco & \\
\hline
\end{tabular}


Tabla 4. Número de granos de los segregantes de cada cruza en cada rango de absorbancia

\begin{tabular}{|c|c|c|c|c|c|c|c|c|c|c|}
\hline Segregantes de las Cruzas & $\begin{array}{c}0,01 \\
- \\
0,10\end{array}$ & $\begin{array}{c}0,11 \\
- \\
0,20\end{array}$ & $\begin{array}{c}0,21 \\
- \\
0,30\end{array}$ & $\begin{array}{c}0,31 \\
- \\
0,40\end{array}$ & $\begin{array}{c}0,41 \\
- \\
0,50\end{array}$ & $\begin{array}{c}0,51 \\
- \\
0,60\end{array}$ & $\begin{array}{c}0,61 \\
- \\
0,70\end{array}$ & $\begin{array}{c}0,71 \\
- \\
0,80\end{array}$ & $\begin{array}{c}\text { Total } \\
\text { de } \\
\text { Granos }\end{array}$ & $\begin{array}{c}\text { Frecuencia } \\
\text { de opacos }\end{array}$ \\
\hline C.R. Huancavelicano x Pool 1 (x)(x) & 5 & 6 & 4 & 5 & 7 & 4 & 13 & 6 & 50 & 0.22 \\
\hline C.R. Huayleño x Pool 1 (x)(x) & 2 & 2 & 7 & 13 & 19 & 7 & 0 & 0 & 50 & 0.08 \\
\hline C.R. Morocho x Pool 1 (x)(x) & 3 & 2 & 2 & 14 & 13 & 10 & 6 & 0 & 50 & 0.10 \\
\hline C.R. Paro x Pool 1(x)(x) & 7 & 1 & 11 & 18 & 6 & 6 & 1 & 0 & 50 & 0.16 \\
\hline C.R. S.G.H. x Pool 1 (x)(x) & 7 & 12 & 6 & 17 & 5 & 3 & 0 & 0 & 50 & 0.38 \\
\hline C.R.Marañon x pool $1(\mathrm{x})(\mathrm{x})$ & 0 & 2 & 6 & 10 & 16 & 10 & 6 & 0 & 50 & 0.04 \\
\hline C.R.Morocho Cajabambino x Pool 1 (x)(x) & 2 & 2 & 5 & 11 & 20 & 6 & 4 & 0 & 50 & 0.08 \\
\hline C.R. Huancavelicano $x$ Pool $2(x)(x)$ & 4 & 7 & 9 & 6 & 3 & 2 & 4 & 0 & 35 & 0.31 \\
\hline C.R. Huayleño x Pool 2 (x)(x) & 3 & 14 & 16 & 5 & 4 & 4 & 4 & 0 & 50 & 0.34 \\
\hline C.R. Morocho IV x Pool $2(\mathrm{x})(\mathrm{x})$ & 1 & 12 & 11 & 12 & 11 & 2 & 0 & 1 & 50 & 0.26 \\
\hline C.R. Paro III x Pool 2 (x)(x) & 9 & 10 & 19 & 12 & 0 & 0 & 0 & 0 & 50 & 0.38 \\
\hline C.R. S.G. Huancavelicano x Pool 2 (x)(x) & 8 & 13 & 13 & 9 & 5 & 1 & 1 & 0 & 50 & 0.42 \\
\hline C.R. Marañon x Pool $2(\mathrm{x})(\mathrm{x})$ & 4 & 15 & 18 & 8 & 4 & 1 & 0 & 0 & 50 & 0.38 \\
\hline C.R. Morocho Cajabambino x Pool 2 (x)(x) & 0 & 2 & 4 & 22 & 15 & 6 & 1 & 0 & 50 & 0.04 \\
\hline Todos los C.R. x Pool 1 (x)(x) & 26 & 27 & 41 & 88 & 86 & 46 & 30 & 6 & 350 & 0.15 \\
\hline Todos los C.R. x Pool 2 (x)(x) & 29 & 73 & 90 & 74 & 42 & 16 & 10 & 1 & 335 & 0.30 \\
\hline TOTAL & 55 & 100 & 131 & 162 & 128 & 62 & 40 & 7 & 685 & 0.22 \\
\hline
\end{tabular}

Valores de Absorbancia de 0.01 a 0.20 se consideran característicos de granos opacos

C.R. S.G.H. = Compuesto racial San Gerónimo Huancavelicano

Tabla 5. Análisis de variancia de los valores de absorbancia de los segregantes de las cruzas

\begin{tabular}{ccccc}
\hline Fuentes & $\begin{array}{c}\text { Grados de } \\
\text { Libertad }\end{array}$ & $\begin{array}{c}\text { Cuadrado } \\
\text { Medio }\end{array}$ & $\begin{array}{c}\text { Valor de F } \\
\text { calculado }\end{array}$ & Pr $>$ F \\
\hline $\begin{array}{c}\text { Cruzas } \\
\text { Dentro de }\end{array}$ & 13 & 0.2961 & $4.15 * *$ & $<0.001$ \\
Cruzas & 123 & 0.0713 & $6.91 * *$ & $<0.001$ \\
Residual & 548 & 0.0103 & & \\
\hline$* *$ diferencias altamente significativas & &
\end{tabular}

Tabla 6. Contrastes de los promedios de absorbancia de los segregantes usando la prueba $\mathrm{f}$

\begin{tabular}{|c|c|c|c|c|c|}
\hline & & $\begin{array}{l}\text { Valor } \\
\text { estimado del } \\
\text { contraste }^{1}\end{array}$ & $\begin{array}{l}\text { Valor de F } \\
\text { tabular } \\
\alpha=0.05\end{array}$ & $\begin{array}{l}\text { Valor de } \mathbf{F} \\
\text { tabular } \\
\alpha=0.01\end{array}$ & $\begin{array}{l}\text { Valor de F } \\
\text { Calculado }\end{array}$ \\
\hline Pool1 vs Pool2 & & 0.6843 & 3.92 & 6.84 & $22.75 * *$ \\
\hline Huancavelicano: & Pool1 vs Pool2 & 0.1485 & 3.92 & 6.84 & $6.37 *$ \\
\hline Huayleño : & Pool1 vs Pool2 & 0.0812 & 3.92 & 6.84 & 2.31 \\
\hline Marañón : & Pool1 vs Pool2 & 0.1864 & 3.92 & 6.84 & $12.18 *$ \\
\hline Morocho Cajabambino : & Pool1 vs Pool2 & 0.0218 & 3.92 & 6.84 & 0.17 \\
\hline Morocho : & Pool1 vs Pool2 & 0.1172 & 3.92 & 6.84 & $4.81 *$ \\
\hline Paro : & Pool1 vs Pool2 & 0.1044 & 3.92 & 6.84 & 3.82 \\
\hline San Gerónimo Huancavelicano : & : Pool1 vs Pool2 & 0.1044 & 3.92 & 6.84 & 3.82 \\
\hline \multicolumn{6}{|c|}{$\begin{array}{l}1 \text { = Valor estimado es calculado como la suma de los promedios del Pool } 1 \text { menos la suma de los promedios del } \\
\text { Pool } 2 . \\
*=\text { diferencias significativas }\end{array}$} \\
\hline
\end{tabular}

${ }^{1}$ Dpto de Biología, Facultad de Ciencias Universidad Nacional Agraria La Molina, Lima - Perú Casilla Postal 12056. Lima 12 - Perú, rcastro@lamolina.edu.pe

${ }^{2}$ Secretaría Técnica de Coordinación con CGIAR (Grupo Consultivo de Investigación Agrícola Internacional). Ministerio de Agricultura. Av. La Molina 1981. Lima 12-Perú. stc_cgiar@inia.gob.pe 